(6) OPEN ACCESS

\title{
Treatment of intracranial aneurysms using the pipeline flex embolization device with shield technology: angiographic and safety outcomes at 1-year follow-up
}

\author{
Mario Martínez-Galdámez, ${ }_{1}^{1}$ Saleh M Lamin, ${ }^{2}$ Konstantinos G Lagios, ${ }^{3}$ Thomas Liebig, \\ Elisa F Ciceri, ${ }^{5,6}$ Rene Chapot, ${ }^{7}$ Luc Stockx ${ }_{1}^{8}$ Swarupsinh Chavda, ${ }^{2}$ \\ Christoph Kabbasch, ${ }_{1}^{4}$ Giuseppe Faragò, ${ }^{5}$ Hannes Nordmeyer, ${ }_{1}^{7}$ Thierry Boulanger, ${ }_{1}^{8}$ \\ Mariangela Piano, ${ }^{9}$ Edoardo P Boccardi ${ }^{9}$
}

For numbered affiliations see end of article.

\section{Correspondence to}

Dr Mario Martínez-Galdámez, Hospital Universitario Fundación Jiménez Diaz, Avda de los Reyes Católicos, Madrid 28040, Spain; mariomgaldamez@hotmail.com

Received 24 June 2018 Revised 25 August 2018 Accepted 29 August 2018 Published Online First 27 September 2018

Check for updates

(C) Author(s) (or their employer(s)) 2019. Re-use permitted under CC BY-NC. No commercial re-use. See rights and permissions. Published by BMJ.

To cite: Martínez Galdámez M, Lamin SM, Lagios KG, et al. J Neurolntervent Surg 2019:11:396-399.
ABSTRACT
Purpose The Pipeline Embolization Device (PED) is a routine first-line treatment option for intracranial aneurysms (IAs). The Pipeline Flex Embolization Device with Shield Technology (Pipeline Shield) is an updated version of the PED which has been modified to include a surface phosphorylcholine biocompatible polymer. Its early technical success and safety have been reported previously. Here, we assessed the long-term safety and efficacy of the Pipeline Shield for the treatment of IAs.

Materials and methods The Pipeline Flex

Embolization Device with Shield Technology (PFLEX) study was a prospective, single-arm, multicenter study for the treatment of unruptured IAs using the Pipeline Shield. The primary endpoint was a major stroke in the territory supplied by the treated artery or neurologic death at 1-year post-procedure. Angiographic outcomes were also assessed by an independent radiology laboratory at 6 months and 1 year.

Results Fifty patients (mean age, 53 years; $82 \%$ female) with 50 unruptured IAs were treated. Mean aneurysm diameter was $8.82 \pm 6.15 \mathrm{~mm}$. Of the target aneurysms, 38/50 (76\%) were small $(<10 \mathrm{~mm}), 11 / 50$ $(22 \%)$ were large $(\geq 10$ and $<25 \mathrm{~mm})$, and $1 / 50(2 \%)$ was giant ( $\geq 25 \mathrm{~mm}$ ). Forty-seven $(94 \%)$ were located in the internal carotid artery and three $(6 \%)$ in the vertebral artery. At 1-year post-procedure, no major strokes or neurologic deaths were reported, and complete occlusion was achieved in $27 / 33$ (81.8\%). There were no instances of aneurysm recurrence or retreatment.

Conclusions Our 1-year follow-up concerning angiographic and safety outcomes corroborate previous evidence that the Pipeline Shield is a safe and effective treatment for IAs.

Trial registration number NCT02390037

\section{INTRODUCTION}

The use of flow diverters has provided a novel, safe, and effective method for treating intracranial aneurysms (IAs). The Pipeline Embolization Device (PED; Medtronic Neurovascular, Irvine, CA, USA), the first neuroendovascular device used for flow diversion, is now a routine treatment option for IAs. ${ }^{1}$ The safety and efficacy of the first-generation
PED have been proven repeatedly. ${ }^{2} 3$ The second generation of the PED, the Pipeline Flex Embolization Device (Pipeline Flex), incorporates a re-sheathing mechanism to allow repositioning and redeployment of the implant. ${ }^{4}$

The latest iteration of the PED, the Pipeline Flex Embolization Device with Shield Technology (Pipeline Shield), has the same design and configuration as the Pipeline Flex, but holds a surface modification where a synthetic phosphorylcholine (PC) biocompatible polymer is covalently bonded to the strands that make up the Pipeline braid ${ }^{5}$ with the aim of reducing thrombogenicity. The PC has been used since 2003 to increase the biocompatibility of vascular stents and has been shown to reduce protein adsorption-thrombin generation. ${ }^{6}{ }^{7}$ In-vitro studies have found the Pipeline Shield to be less thrombogenic than other flow diverters. ${ }^{8}$

We previously reported the periprocedural outcomes and early safety results of using the Pipeline Shield to treat unruptured IAs. ${ }^{9}$ We found that the Pipeline Shield demonstrated high technical success with no major short-term complications within 30 days of the procedure. ${ }^{9}$ We now report on the long-term safety and efficacy of treatment with Pipeline Shield at 1-year follow-up in the PFLEX study.

\section{MATERIALS AND METHODS}

\section{Study design and participants}

The PFLEX study was a prospective, single-arm, multicenter study for the treatment of unruptured IAs using Pipeline Shield. From March to October 2015, 50 patients with a total of 50 unruptured target aneurysms, treated at seven experienced neurovascular centers in six European countries, were enrolled in the PFLEX study. Complete enrollment, inclusion, and exclusion criteria were previously described. ${ }^{9}$ In brief, patients aged $18-80$ years with unruptured IAs in the internal carotid artery or vertebral artery segment, up to and including the posterior inferior cerebellar artery, were included. Patients that had a subarachnoid hemorrhage, recent surgery, vessel tortuosity, stenosis, or any 
Table 1 Anti-platelet regimen at 30 days and 1-year post-procedure

\begin{tabular}{|c|c|}
\hline 30-day follow-up & $\mathrm{n} / \mathrm{N}(\%)$ \\
\hline $\begin{array}{l}\text { Patients prescribed any anti-platelet therapy } \geq 30 \text {-days post- } \\
\text { procedure }\end{array}$ & $50 / 50(100)$ \\
\hline $\begin{array}{l}\text { Patients prescribed dual anti-platelet therapy (DAPT) } \geq 30 \text {-days } \\
\text { post-procedure }\end{array}$ & $50 / 50(100)$ \\
\hline Aspirin $100 \mathrm{mg}+$ clopidogrel $150 \mathrm{mg}$ & $2 / 50(4)$ \\
\hline Aspirin $100 \mathrm{mg}+$ clopidogrel $75 \mathrm{mg}$ & $28 / 50(56)$ \\
\hline Aspirin $100 \mathrm{mg}+$ prasugrel $10 \mathrm{mg}$ & $2 / 50(4)$ \\
\hline Aspirin 200mg+clopidogrel $75 \mathrm{mg}$ & $2 / 50(4)$ \\
\hline Aspirin $325 \mathrm{mg}+$ clopidogrel $75 \mathrm{mg}$ & $1 / 50(2)$ \\
\hline Aspirin $325 \mathrm{mg}+$ prasugrel $5 \mathrm{mg}$ & $1 / 50(2)$ \\
\hline Aspirin $75 \mathrm{mg}+$ clopidogrel $75 \mathrm{mg}$ & $10 / 50(20)$ \\
\hline Aspirin 80mg+clopidogrel $75 \mathrm{mg}$ & $4 / 50(8)$ \\
\hline $\begin{array}{l}\text { Patients prescribed single anti-platelet therapy } \geq 30 \text {-days post- } \\
\text { procedure }\end{array}$ & $0 / 50(0)$ \\
\hline 1-year follow-Up & $\mathrm{n} / \mathrm{N}(\%)$ \\
\hline $\begin{array}{l}\text { Patients prescribed any anti-platelet therapy at } 1 \text {-year post- } \\
\text { procedure }\end{array}$ & $44 / 50(88.00)$ \\
\hline $\begin{array}{l}\text { Patients prescribed dual anti-platelet therapy (DAPT) at 1-year } \\
\text { post-procedure }\end{array}$ & 9/44 (20.45) \\
\hline Aspirin $100 \mathrm{mg}+$ clopidogrel $75 \mathrm{mg}$ & $6 / 44(13.64)$ \\
\hline Aspirin $75 \mathrm{mg}+$ clopidogrel $75 \mathrm{mg}$ & $1 / 44(2.27)$ \\
\hline Aspirin $80 \mathrm{mg}+$ clopidogrel $75 \mathrm{mg}$ & $2 / 44(4.55)$ \\
\hline $\begin{array}{l}\text { Patients prescribed single anti-platelet therapy at } 1 \text {-year post- } \\
\text { procedure }\end{array}$ & $35 / 44(79.55)$ \\
\hline Aspirin $100 \mathrm{mg}$ & $21 / 44(47.73)$ \\
\hline Aspirin $200 \mathrm{mg}$ & $1 / 44(2.27)$ \\
\hline Aspirin $300 \mathrm{mg}$ & $1 / 44(2.27)$ \\
\hline Aspirin $325 \mathrm{mg}$ & $1 / 44(2.27)$ \\
\hline Aspirin $75 \mathrm{mg}$ & $8 / 44(18.18)$ \\
\hline Aspirin $80 \mathrm{mg}$ & $1 / 44(2.27)$ \\
\hline Clopidogrel $75 \mathrm{mg}$ & $2 / 44(4.55)$ \\
\hline
\end{tabular}

other Pipeline Shield contraindication were excluded from the study.

\section{Treatment description}

Peri-procedural data were previously described. ${ }^{9}$ Antiplatelet therapy was administered per the local institution's protocol. Prior to the procedure, 46/50 (92\%) patients received dual antiplatelet therapy (DAPT - aspirin + clopidogrel/prasugrel) and $4 / 50(8 \%)$ patients received clopidogrel alone. In most cases, Pipeline Shield was deployed through a microcatheter (Marksman or Echelon, ev3, Irvine, CA; Excelsior, Stryker, Fremont, CA; Headway, MicroVention, Tustin, CA; or Reverse Microcatheter, Reverse, Irvine, CA) using a triaxial guide catheter system. 50/50 (100\%) patients were prescribed DAPT between $\geq 1$-month and $\leq 1$-year post-procedure. See table 1 for a complete description of the anti-aggregation regimen.

\section{Follow-up assessments}

Patients had a follow-up office visit or telephone call at 30 days, 6 months, and 1 year after Pipeline Shield placement. Angiographic assessments were performed at 6 months and/or 1 year after Pipeline Shield placement per institutional standard of care and were analyzed by an independent core radiology laboratory.

\section{Study endpoints}

The primary study endpoint was the occurrence of a major stroke in the territory supplied by the treated artery or neurologic death within 1 year of the procedure. The secondary endpoint was the rate of Pipeline Flex Embolization Device with Shield Technology-related neurologic adverse events within 1 year of the procedure. Investigators were required to report all serious adverse events, adverse events with an underlying neurologic cause, and events deemed related to the study device or procedure. Safety incidence rates or proportions for neurologic adverse events were calculated based on the number of participants who underwent the study procedure and in whom an attempt to implant the study device was made.

For the purpose of this study protocol, stroke was defined as a focal neurological deficit of presumed vascular origin persisting $>24$ hours from symptom onset and a neuro-imaging study or other quantitative study that did not indicate an alternative etiology. The 24 hours criterion was excluded if the patient underwent cerebrovascular surgery or died during the first 24 hours following symptom onset. Stroke severity was graded by the investigator as major or minor. Major stroke was defined as a stroke that was persistent after 7 days and associated with an increase of $\geq 4$ points on the National Institutes of Health Stroke Scale (NIHSS) score. Minor stroke was defined as a stroke that resolved completely within 7 days or increased the NIHSS score of the patient by $\leq 3$ points. An independent Clinical Events Committee (CEC) adjudicated all reportable adverse events that occurred within 1 year after the procedure period.

The independent core radiology laboratory assessed aneurysm occlusion, parent artery stenosis, and device migration at 6 months and 1 year after the implant procedure. Aneurysm occlusion was classified using the Raymond-Roy Scale: class I=complete occlusion; class II=residual neck; and class III =residual aneurysm. ${ }^{10}$ Parent artery stenosis was assessed by classifying into four categories: $0 \%-25 \%,>25 \%-50 \%,>50 \%-75 \%$, and $>75 \%$ stenosis.

\section{Statistical analysis}

As previously described, data from the PFLEX study were analyzed based on the intention-to-treat population. ${ }^{9}$ Discrete variables were summarized using the frequency and percentage. Continuous variables were summarized using the number of observations and the mean, SD, median, minimum, and maximum values as appropriate. All statistical analyses were performed using SAS (version 9.2 or higher; SAS Institute, Cary, $\mathrm{NC})$.

\section{RESULTS}

Fifty patients with 50 unruptured target IAs were treated. Forty-nine (98\%) were saccular and one (2.0\%) was fusiform. The mean patient age was $53.0 \pm 13.01$ years, and 41 (82\%) patients were female. The mean target aneurysm diameter was $8.82 \pm 6.15 \mathrm{~mm}$. Of the target aneurysms, 38/50 (76.0\%) were small $(<10 \mathrm{~mm}), 11 / 50(22.0 \%)$ were large $(\geq 10$ and $<25 \mathrm{~mm})$, and $1 / 50(2.0 \%)$ was giant $(\geq 25 \mathrm{~mm})$ in size. Forty-seven $(94 \%)$ aneurysms were located in the internal carotid artery (ICA), and three $(6 \%)$ were located in the vertebral artery. Device deployment was successful in all patients. The total number of Pipeline Shields utilized was 56 , with a mean of $1.12 \pm 0.39$ per aneurysm participant. Of these, $3 / 56$ (5.4\%) did not fully deploy and were therefore not implanted.

No major strokes or neurologic deaths were reported at 1 year after the procedure (table 2). There were a total of seven device-related neurologic adverse events reported: six cases of 


\begin{tabular}{ll}
\hline $\begin{array}{l}\text { Table } 2 \\
\text { procedure }\end{array}$ & Primary and secondary safety outcomes at 1-year post- \\
\hline Endpoint & Event rate $\mathrm{n} / \mathrm{N}(\%)(95 \% \mathrm{Cl})$ \\
\hline $\begin{array}{l}\text { Major stroke in the territory supplied by the } \\
\text { treated artery or neurological death }\end{array}$ & $0 / 50(0 \%)(0 \%, 5.8 \%)$ \\
\hline $\begin{array}{l}\text { Major stroke in the territory supplied by the } \\
\text { treated artery }\end{array}$ & $0 / 50(0 \%)(0 \%, 5.8 \%)$ \\
\hline $\begin{array}{l}\text { Neurological death } \\
\text { Pipeline Flex embolization device with shield } \\
\text { technology-related neurologic adverse event } \\
\text { rate }\end{array}$ & $7 / 50(14.0 \%)(5.8 \%, 26.7 \%)$ \\
\hline
\end{tabular}

in-stent stenosis which were non-serious adverse events; and one case of ICA thrombosis which was a serious adverse event. The ICA thrombosis was identified during diagnostic angiography for a second aneurysm at 63 days after Pipeline Shield implantation. The patient was noted to have a left ICA thrombosis with excellent collateral formation. The parent artery was patent distal to the Pipeline Shield Device, which was located superior to the posterior communicating artery. The thrombosis appeared to have initiated at the parent artery and then extended into the device. The antiplatelet assay showed suboptimal platelet inhibition. As the patient was asymptomatic and had no neurological deficits, no intervention was undertaken, and further dual antiplatelet therapy was prescribed $(100 \mathrm{mg}$ aspirin and $75 \mathrm{mg}$ clopidogrel daily). In addition, three procedure-related serious adverse events (headache, diplopia, and retroperitoneal hematoma) and six procedure-related non-serious adverse events (carotid artery dissection, access site hematoma, cerebral infarction, headache, and two events of nausea) were reported.

Complete aneurysm occlusion was achieved in 29/38 (76.3\%) and $27 / 33(81.8 \%)$ target aneurysms at 6-months and 1-year follow-up, respectively (table 3 ). There were no instances of target aneurysm recurrence or retreatment $(0 / 50,0 \%)$ reported through 1-year follow-up. A summary of parent artery stenosis

Table 3 Aneurysm occlusion and parent artery stenosis at 6-months and 1-year post-procedure

\begin{tabular}{lll}
\hline Aneurysm occlusion & 6 months $\mathrm{n} / \mathrm{N}(\%)$ & 1 year $\mathrm{n} / \mathrm{N}(\%)$ \\
\hline Target aneurysm & & \\
\hline Complete occlusion & $29 / 38(76.3)$ & $27 / 33(81.8)$ \\
\hline Residual neck & $5 / 38(13.2)$ & $2 / 33(6.1)$ \\
\hline Residual aneurysm & $4 / 38(10.5)$ & $4 / 33(12.1)$ \\
\hline Cannot determine* & 1 & 1 \\
\hline All aneurysms & & $27 / 33(81.8)$ \\
\hline Complete occlusion & $31 / 40(77.5)$ & $2 / 33(6.1)$ \\
\hline Residual neck & $5 / 40(12.5)$ & $4 / 33(12.1)$ \\
\hline Residual aneurysm & $4 / 40(10.0)$ & 1 \\
\hline Cannot determine* & 1 & \\
\hline Parent artery stenosis & & $28 / 32(87.5)$ \\
\hline $0 \%-25 \%$ & $29 / 36(80.6)$ & $3 / 32(9.4)$ \\
\hline$>25 \%-50 \%$ & $5 / 36(13.9)$ & 0 \\
\hline$>50 \%-75 \%$ & $1 / 36(2.8)$ & $1 / 32(3.1)$ \\
\hline$>75 \%$ & $1 / 36(2.8)$ & 2 \\
\hline Cannot determine* & 3 & \\
\hline
\end{tabular}

*Imaging was performed as per standard of care in 39 patients at 6 months, and in 34 patients at 1 year. Occlusion rate was indeterminate in one patient of 50 . at follow-up is presented in table 3 . There was only one case of $>75 \%$ parent artery stenosis at both 6-months and 1-year follow-up. This case was adjudicated by the CEC as an internal carotid artery thrombosis as previously discussed, and described by the core laboratory to possibly be related to a dissection in the cervical ICA leading to thrombosis throughout the entire carotid, including the stent. All other parent artery stenosis cases were determined to be in-stent stenosis due to intimal hyperplasia.

\section{DISCUSSION}

The PFLEX study is the first multicenter clinical study describing the use of the Pipeline Shield. We previously reported peri-procedural outcomes and early safety results at 30-day follow-up from the study with no major strokes or neurological death. ${ }^{9}$ Based on 1-year follow-up results, the safety of Pipeline Shield has been corroborated for long-term outcomes, with the same rate of primary-end point events previously reported at 30-days post-procedure and with no cases of major stroke or neurological death occurring during this period. The Pipeline Shield was designed on the theoretical basis of a more biocompatible implant to mitigate against thrombogenic events. Some in vitro studies have demonstrated promising results, showing reduced thrombogenicity. ${ }^{5811}$ The lack of major thromboembolic events in the PFLEX study may support earlier in-vitro evidence of Pipeline Shield's low thrombogenicity.

The long-term safety outcomes of this study are comparable to those reported utilizing earlier generations of the PED. The IntrePED Study, the largest clinical study of PED to date, reported major morbidity or mortality in 50/793 (6.3\%) of patients at 30-days post-treatment. The ischemic stroke rate was $4.7 \%$, with $70 \%$ of strokes occurring within 30 days. $^{12}{ }^{13}$ The Intracranial Treatment of Aneurysms Trial (PITA) reported that $2 / 31(6.5 \%)$ patients had a major stroke or neurological complication at 6 -months post-treatment. ${ }^{14}$ The PED for Uncoilable or Failed Aneurysms (PUFS) multicenter clinical trial reported major stroke or neurological death in 6/107 (5.6\%) of patients at 180 days. $^{3}$ The Aneurysm Study of Pipeline in an Observational Registry (ASPIRe) study reported a combined neurological morbidity/mortality rate of $6.8 \%$ (13/191 patients). Ischemic stroke rate was $4.7 \%$, with all major strokes occurring within 30 days of treatment. ${ }^{2}$

Follow-up angiography in the PFLEX study showed high rates of aneurysm occlusion and low rates of in-stent stenosis at 1-year post-procedure. There were no reports of target aneurysm recurrence or retreatment after complete occlusion of the aneurysms. These findings are consistent with the PITA study of first-generation PED devices, which reported complete aneurysm occlusion in $28 / 30(93.3 \%)$ of patients at 6-month follow-up ${ }^{14}$ and would suggest that the PC surface modification does not adversely affect either porosity or neointimal growth. In comparison, the ASPIRe study reported complete occlusion in 33/42 (78.6\%) of patients at 6 months, with $11(5.8 \%)$ patients requiring retreatment. ${ }^{2}$ The 5 -year follow-up of the PUFS study reported complete occlusion in $79 / 91(86.8 \%)$ at 1 year, $71 / 76(93.4 \%)$ at 3 years, and $60 / 63$ $(95.2 \%)$ at 5 years post-treatment, and 6/106 (5.7\%) of aneurysms required retreatment. ${ }^{15}$

Flow diverters induce a neo-endothelial reaction along the aneurysm neck, which has been associated with aneurysm occlusion and in some cases in-stent stenosis. In-stent stenosis of flow diverters is frequently under-diagnosed, usually having an asymptomatic and reversible evolution. Chalouhi et al reported in-stent stenosis in 21/139 (15.8\%) of patients treated with the first-generation Pipeline device, during a mean follow-up of 6.7 months (range, 3-24 months). ${ }^{16}$ The stenosis was mild 
$(<50 \%)$ in 11 patients, moderate $(50 \%-75 \%)$ in five patients, and severe $(>75 \%)$ in six patients. None were symptomatic or required further intervention. The rates of in-stent stenosis in the PUFS study during the first year after the procedure were: $<25 \%$ stenosis in $85 / 91(93.4 \%)$ of patients, $>25 \%-$ $50 \%$ stenosis in 1/91 (1.1\%), $>50 \%-75 \%$ stenosis in $1 / 91$ $(1.1 \%)$, and $>75 \%$ stenosis $1 / 91(1.1 \%) .{ }^{15}$ Stenosis was indeterminate in $3 / 91(3.3 \%)$ of those cases. In a recent publication, Matsuda et al compared the neointimal patterns formed in a swine model treated with Pipeline Flex and Pipeline Shield. ${ }^{11}$ The authors concluded that, in comparison with Pipeline Flex, Pipeline Shield results in earlier neointimal formation, resulting in reduced thrombosis, reduced late neointimal hyperplasia, and a reduced in-stent stenosis rate. Furthermore, a recent preclinical study has demonstrated reduced intimal hyperplasia without reducing aneurysm occlusion rates by using the Shield technology. ${ }^{17}$

Our results confirm that Pipeline Shield maintains its low rate of significant stenosis in a clinical setting. In the PFLEX study, at 1-year post-procedure, only $3 / 32$ (9.4\%) cases with angiographic data available were reported to have $>25 \%-50 \%$ in-stent stenosis, and only one single case with $>50 \%$ in-stent stenosis. These findings indicate that Pipeline Shield may have a 'more benign' pattern of significant in-stent stenosis than the previous generation of the device, inducing clot formation less frequently.

As previously reported, a limitation of this study is that the target aneurysms were primarily small in size $(<10 \mathrm{~mm}$ in diameter) and located in the ICA. ${ }^{9}$ Small aneurysms in the ICA are reported to have lower complication rates than other anterior or posterior circulation aneurysms, ${ }^{13}$ which could have biased our safety outcomes. Furthermore, missing angiographic data on several patients may misrepresent the 1-year occlusion rates, and we did not gather antiplatelet assays post-procedurally which could have been used to determine the extent to which PC decreases dependence on antiplatelet therapy for the reduction of thrombogenicity.

\section{CONCLUSION}

The PFLEX study is the first prospective study to evaluate the use of the Pipeline Shield device. Our results show that there was no occurrence of major stroke or neurologic death at 1 -year post-procedure. Observed rates of aneurysm occlusion and in-stent stenosis were comparable to previously published results with the earlier generation devices, demonstrating that the Pipeline Shield device is safe and effective for the treatment of IAs. In our cohort, there were no cases without antiagreggation and each institution applied their daily basis antiplatelet protocol. With the currently available evidence and the results of this clinical study, standard antiplatelet regimens should be still recommended.

\section{Author affiliations}

Department of Interventional Neuroradiology/Endovascular Neurosurgery, Fundación Jiménez-Díaz, Madrid, Spain

${ }^{2}$ Queen Elizabeth Hospital Birmingham, Edgbaston, UK

${ }^{3}$ Department of Interventional Neuroradiology, Hellenic Air Force Hospital, Goudi, Greece

${ }^{4}$ Department of Neuroradiology, Institut für Neuroradiologie, Charite, Berlin, Germany

${ }^{5}$ Department of Interventional Neuroradiology, Foundation Neurological Institution 'C Besta', Milan, Italy

${ }^{6}$ Azienda Ospedaliera Universitaria Integrata, Verona, Italy

${ }_{7}^{7}$ Department of Neuroradiology, Alfried Krupp Krankenhaus, Essen, Germany
${ }^{8}$ Department of Neuroradiology, Ziekenhuizen Oost-Limburg, Genk, Belgium ${ }^{9}$ Department of Neuroradiology, Ospedale Niguarda Ca' Granda, Milan, Italy

Acknowledgements We would like to acknowledge the editing and formatting services provided by Medtronic

Contributors All authors made substantial contributions to the conception or design of the work; or the acquisition, analysis, or interpretation of data for the work; and drafted the work or revised it critically for important intellectual content; and provided final approval of the version to be published; and agree to be accountable for all aspects of the work in ensuring that questions related to the accuracy or integrity of any part of the work are appropriately investigated and resolved.

Funding This study was funded by Medtronic.

Competing interests MM-G serves as a proctor and consultant for Medtronic. SML proctors and consults for Medtronic. TL previously consulted and proctored for Covidien, Stryker, and MicroVention, and currently serves as a proctor and consultant for Sequent Medical. EPB receives honoraria from Medtronic and serves as a consultant for Medtronic.

Patient consent Not required.

Ethics approval 7 IRBs at the 7 institutions involved in the PFLEX study.

Provenance and peer review Not commissioned; externally peer reviewed.

Open access This is an open access article distributed in accordance with the Creative Commons Attribution Non Commercial (CC BY-NC 4.0) license, which permits others to distribute, remix, adapt, build upon this work non-commercially, and license their derivative works on different terms, provided the original work is properly cited, appropriate credit is given, any changes made indicated, and the use is non-commercial. See: http://creativecommons.org/licenses/by-nc/4.0/.

\section{REFERENCES}

1 Jiang B, Paff M, Colby GP, et al. Cerebral aneurysm treatment: modern neurovascular techniques. Stroke Vasc Neurol 2016;1:93-100.

2 Kallmes DF, Brinjikji W, Boccardi E, et al. Aneurysm Study of Pipeline in an Observational Registry (ASPIRe). Interv Neurol 2016;5:89-99.

3 Becske T, Kallmes DF, Saatci I, et al. Pipeline for uncoilable or failed aneurysms: results from a multicenter clinical trial. Radiology 2013;267:858-68.

4 Aguilar-Salinas P, Brasiliense LB, Gonsales D, et al. Evaluation of pipeline flex delivery system for the treatment of unruptured aneurysms. Expert Rev Med Devices 2016;13:885-97.

5 Girdhar G, Li J, Kostousov L, et al. In-vitro thrombogenicity assessment of flow diversion and aneurysm bridging devices. J Thromb Thrombolysis 2015;40:437-43.

6 Nakabayashi N, Williams DF. Preparation of non-thrombogenic materials using 2-methacryloyloxyethyl phosphorylcholine. Biomaterials 2003;24:2431-5.

7 Ye SH, Jang YS, Yun YH, et al. Surface modification of a biodegradable magnesium alloy with phosphorylcholine (PC) and sulfobetaine (SB) functional macromolecules for reduced thrombogenicity and acute corrosion resistance. Langmuir 2013;29:8320-7.

8 Hagen MW, Girdhar G, Wainwright J, et al. Thrombogenicity of flow diverters in an ex vivo shunt model: effect of phosphorylcholine surface modification. J Neurointerv Surg 2017:9:1006-11

9 Martínez-Galdámez M, Lamin SM, Lagios KG, et al. Periprocedural outcomes and early safety with the use of the Pipeline Flex Embolization Device with Shield Technology for unruptured intracranial aneurysms: preliminary results from a prospective clinical study. J Neurointerv Surg 2017;9:772-6.

10 Roy D, Milot G, Raymond J. Endovascular treatment of unruptured aneurysms. Stroke 2001:32:1998-2004

11 Matsuda Y, Chung J, Lopes DK. Analysis of neointima development in flow diverters using optical coherence tomography imaging. J Neurointerv Surg 2018;10:162-7.

12 Anon. Erratum. AJNR Am J Neuroradiol 2015;36:E39-40.

13 Kallmes DF, Hanel R, Lopes $D$, et al. International retrospective study of the pipeline embolization device: a multicenter aneurysm treatment study. AJNR Am J Neuroradiol 2015;36:108-15

14 Nelson PK, Lylyk P, Szikora I, et al. The pipeline embolization device for the intracranial treatment of aneurysms trial. AJNR Am J Neuroradiol 2011;32:34-40.

15 Becske T, Brinjikji W, Potts MB, et al. Long-term clinical and angiographic outcomes following pipeline embolization device treatment of complex internal carotid artery aneurysms: five-year results of the pipeline for uncoilable or failed aneurysms trial. Neurosurgery 2017;80:40-8

16 Chalouhi N, Polifka A, Daou B, et al. In-pipeline stenosis: incidence, predictors, and clinical outcomes. Neurosurgery 2015;77:875-9. discussion 79 .

17 Caroff J, Tamura T, King RM, et al. Phosphorylcholine surface modified flow diverter associated with reduced intimal hyperplasia. J Neurointerv Surg 2018:doi: 10.1136/ neurintsurg-2018-013776 [Epub ahead of print 06 Mar 2018]. 